
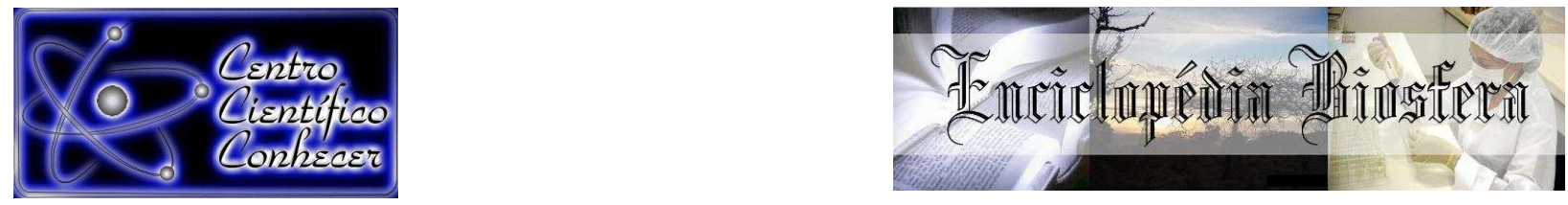

\title{
INFECÇÃO PELO Toxoplasma gondii E PELO VÍRUS DA IMUNODEFICIÊNCIA FELINA EM GATOS DOMÉSTICOS (Felis catus)
}

Rebeka Cristine de Bastos Costa ${ }^{1}$, Valéria de Sá Jayme ${ }^{2}$, Guido Fontgalland Coelho Linhares $^{2}$, Osvaldo José Silveira Neto ${ }^{3}$, Thawanne Delefrate Queiroz ${ }^{4}$

1 Mestre em Ciência Animal pela Escola de Veterinária e Zootecnia, Universidade

Federal de Goiás, Goiânia-GO, Brasil, e-mail: bekacbc@hotmail.com

2 Professor Doutor do Departamento de Medicina Preventiva da Escola de

Veterinária e Zootecnia da Universidade Federal de Goiás, Goiânia-GO, Brasil

3 Professor Doutor da Universidade Estadual de Goiás, Goiânia-GO, Brasil

4 Graduanda em Medicina Veterinária pela Escola de Veterinária e Zootecnia da Universidade Federal de Goiás, Goiânia-GO, Brasil

\section{Recebido em: 08/09/2015 - Aprovado em: 14/11/2015 - Publicado em: 01/12/2015 DOI: http://dx.doi.org/10.18677/Enciclopedia_Biosfera_2015_178}

\begin{abstract}
RESUMO
O gato doméstico (Felis catus) é um animal de companhia, com crescente valorização como pet, o que tem proporcionado o aumento de sua população nos domicílios brasileiros. Apresenta elevada importância na Saúde Pública, participando do ciclo de algumas zoonoses, dentre as quais a toxoplasmose. Constitui-se em um dos hospedeiros definitivos do Toxoplasma gondii, protozoário responsável por esta enfermidade. O gato doméstico também pode ser acometido pelo vírus da imunodeficiência felina (FIV) e devido à imunossupressão causada por tal patógeno pode vir a desenvolver doenças oportunistas. A infecção simultânea do T. gondii e o FIV pode predispor ao desenvolvimento agudo da toxoplasmose nos felídeos. Nesta revisão foram abordados aspectos etiológicos, epidemiológicos, clínicos, de diagnóstico e profiláticos destas duas enfermidades. Maior enfoque foi dado aos resultados encontrados no Brasil e no mundo relativos à frequência de anticorpos anti- $T$. gondii, à detecção de oocistos do $T$. gondii nas fezes destes animais, a dados sorológicos para o vírus da imunodeficiência felina em gatos domésticos, à coinfecção entre estes dois patógenos, além dos possíveis fatores associados às infecções. Tal abordagem buscou demonstrar o impacto das duas infecções na Medicina Veterinária e na Saúde Pública.
\end{abstract}

PALAVRAS-CHAVE: AIDS felina, frequência, oocisto, toxoplasmose.

\section{Toxoplasma gondii INFECTION AND THE FELINE IMMUNODEFICIENCY VIRUS IN DOMESTIC CATS (Felis catus) - LITERATURE REVIEW}

\begin{abstract}
The domestic cat (Felis catus) is a companion animal, with growing appreciation as a pet, which has provided the increase of its population in Brazilian households. It has high importance in Public Health, participating in the cycle of some zoonoses, among which toxoplasmosis. It is one of the definitive hosts of Toxoplasma gondii parasite responsible for this disease. The domestic cat can also be affected by feline immunodeficiency virus (FIV) and due to immunosuppression caused by this pathogen can go on to develop opportunistic infections. Simultaneous infection of $T$.
\end{abstract}


gondii and FIV may predispose to acute development of toxoplasmosis in felines. In this review we were addressed etiological, epidemiological, clinical, diagnostic and prophylactic of these two diseases. More focus was given to results found in Brazil and in the world on the frequency of anti- $T$. gondii, the detection of $T$. gondii oocysts in the feces of these animals, the serological data to feline immunodeficiency virus infection in domestic cats, the co-infection of both pathogens, in addition to the possible factors associated with infection. This approach sought to demonstrate the impact of the two infections in Veterinary Medicine and Public Health.

KEYWORDS: feline AIDS, frequency, oocyst, toxoplasmosis.

\section{INTRODUÇÃO}

A toxoplasmose é uma zoonose cosmopolita, causada pelo Toxoplasma gondii, protozoário intracelular obrigatório, capaz de infectar e se replicar em qualquer célula nucleada dos seus hospedeiros intermediários, mamíferos e aves. Seus hospedeiros definitivos são os membros da família dos felídeos, como o gato doméstico (Felis catus) (DUBEY, 2010). Destacando-se tanto na Medicina Veterinária e Humana, a toxoplasmose, pode causar aborto ou doença congênita em seus hospedeiros intermediários. Devido à sua importância como agente causador de zoonose, o T. gondii tem sido, dentre os coccídeos, o mais intensamente estudado (TENTER et al., 2000).

São escassos os dados sobre a frequência desse patógeno em gatos no Brasil, mas, sabe-se que a infecção está difundida nos animais em todo o mundo e estima-se que $90 \%$ dos animais domésticos e silvestres brasileiros apresentem anticorpos para o protozoário (DUBEY et al., 2012).

Por serem hospedeiros definitivos desse protozoário, os gatos, na maioria das vezes são assintomáticos. Ressalta-se que o vírus da imunodeficiência felina (FIV), um agente imunossupressor, em conjunto com a toxoplasmose pode levar o $F$. catus a desenvolver sintomas clínicos, como pneumonia, podendo ocasionar o óbito. Felinos duplamente infectados por $T$. gondii e FIV também tendem a apresentar soroprevalência mais elevada para toxoplasmose, além do desenvolvimento agudo da doença com possível reeliminação de oocistos nas fezes. Este fenômeno é raro em gatos naturalmente infectados, pois poucos são os relatos de toxoplasmose fulminante em gatos com FIV (DUBEY, 2010).

Além da infecção pelo FIV, já foram avaliados como outros fatores associados à toxoplasmose em gatos domésticos a idade, o gênero e o estilo de vida livre. Ressalta-se que quanto maior o número de gatos infectados por bradizoítos presentes em roedores e aves, maior a chance de eliminação de oocistos, que quando esporulados podem contaminar alimentos e água, o que aumenta a chance da infecção humana pelo T. gondii (DUBEY, 2010).

Diante disto, objetivou-se realizar uma revisão de literatura abrangendo resultados encontrados no Brasil e no mundo referentes à frequência de anticorpos anti- $T$. gondii, à detecção de oocistos do $T$. gondii nas fezes destes animais, aos dados sorológicos para o vírus da imunodeficiência felina em gatos domésticos ( $F$. catus) e à coinfecção entre eles, buscando-se também dados sobre os possíveis fatores associados às infecções.

\section{CARACTERÍSTICAS BIOLÓGICAS DO TOXOPLASMA GONDII}

O T. gondii foi descrito pela primeira vez em roedores, em 1908, na Tunísia, África. Seu nome é derivado da sua morfologia, toxo = arco, plasma = forma e por ter sido descoberto em um roedor da região do Gundi (DUBEY, 2008). Em 
1942, a toxoplasmose foi detectada em gatos e em 1967 foi demonstrado que o protozoário pode ser contraído pela ingestão de oocistos eliminados nas fezes dos felídeos. A descoberta destes como hospedeiros definitivos, em 1970, levou a elucidação do ciclo biológico completo da toxoplasmose. Assim, o T. gondii é um coccídeo que tem os felídeos como hospedeiros definitivos e os animais de sangue quente como hospedeiros intermediários (DUBEY, 2008), é pertencente ao filo Apicomplexa, subfamília Toxoplasmatinae, gênero Toxoplasma, sendo o único representante deste (DUBEY, 2010).

Tal protozoário possui ciclo de vida heteroxeno (figura 1), apresenta fase assexuada de desenvolvimento em vários tecidos dos carnívoros, herbívoros, onívoros; e a fase de desenvolvimento sexuada ocorre no intestino de felídeos (TENTER et al., 2000). Três fases distintas e infecciosas para ambos os tipos de hospedeiros estão presentes: taquizoítos, bradizoítos (cistos tissulares) e esporozoítos (oocistos) (DUBEY et al., 1998). Os hospedeiros podem adquirir a toxoplasmose por diferentes vias, como a horizontal, por ingestão oral de oocistos esporulados no ambiente, que podem contaminar água, vegetais, frutas e já foi demonstrada a transmissão por vetores mecânicos (DUBEY, 2010).

A transmissão também pode ocorrer pela ingestão de cistos tissulares presentes na carne crua ou mal cozida e verticalmente por transmissão transplacentária de taquizoítos. Estes ainda podem ser transmitidos pelo leite da mãe para o filho e por transplante de sangue ou órgãos. Quando hospedeiros definitivos se contaminam após a ingestão de qualquer uma das três fases, poderá ocorrer o ciclo enteropitelial no intestino e com consequente liberação de oocistos imaturos no ambiente, fase esta conhecida como sexuada. No meio ambiente, entre um a cinco dias, em condições adequadas de temperatura e pressão, o oocisto esporula sofrendo maturação, sendo então infeccioso aos hospedeiros e contendo em seu interior dois esporocistos com quatro esporozoítos cada, os quais são infectantes (DUBEY, 2010).

A fase assexuada ocorre quando hospedeiros intermediários suscetíveis se infectam com qualquer uma das três fases mencionadas. Após a esporulação dos oocistos no ambiente, caso sejam ingeridos, ocorrerá a excistação, na presença de sais biliares e da tripsina, o que leva à ruptura dos esporocistos e liberação dos esporozoítos, que poderão penetrar nos enterócitos e a partir daí ser denominados de taquizoítos (DUBEY et al., 1998).

Os taquizoítos podem invadir vários tipos de células do organismo formando um vacúolo parasitóforo, multiplicando-se rapidamente por endodiogenia nas diferentes células nucleadas do hospedeiro, o que caracteriza a fase aguda da infecção. A última geração de taquizoítos forma os bradizoítos, os quais também se reproduzem por endodiogenia só que se desenvolvem lentamente em cistos tissulares, o que caracteriza a doença crônica (DUBEY, 2010).

\section{ASPECTOS EPIDEMIOLÓGICOS}

Dentre os felídeos, o gato doméstico ( $F$. catus) apresenta elevada importância, pois é considerado um animal de companhia, o que proporcionou o aumento de sua população nos domicílios brasileiros, chegando a 22,1 milhões, em 2013 (IBGE, 2015). Contudo, o potencial zoonótico de tal espécie é desconhecido pela maioria das pessoas. Desta forma, vários tutores permitem que seus animais circulem livremente pelas ruas, podendo ingerir presas contaminadas com $0 T$. gondii, com consequente possibilidade de eliminação de oocistos no ambiente (DABRITZ et al., 2010). 
Tal condição poderá levar à contaminação dos alimentos, água, terra e outros animais, fazendo com que os oocistos esporulados sejam de grande importância na infecção para os hospedeiros intermediários (DUBEY, 2010). Por conseguinte, alguns autores associam o número de gatos infectados na região à chance dos hospedeiros se contaminarem (LOPES et al., 2009), o que faz com que - F. catus seja considerado o principal responsável pela perpetuação da toxoplasmose nos grandes centros, pois é o representante doméstico dos hospedeiros definitivos (VARGAS, 2006). Assim, a infecção pelo T. gondii em gatos apresenta grande importância na vigilância epidemiológica (DUBEY et al., 2008).

Diversos trabalhos têm buscado associar os resultados sorológicos nesses animais ao risco dos hospedeiros se contaminarem com os oocistos do protozoário. Em gatos domésticos os anticorpos contra $T$. gondii já foram detectados, sendo elevada a soroprevalência, chegando a 95,5\% de positivos (ALKAPPANY et al., 2011) dependendo, entre outros fatores, do tipo de alimentação e do acesso à rua (TENTER et al., 2000).

No Brasil, diversos autores estudaram a soropositividade do T. gondii em F. catus, sendo que diferentes testes foram utilizados e vários fatores associados à infecção por tal protozoário. Os resultados encontrados estão distribuídos na tabela 1 , os quais variaram de $5,6 \%$ a $57,14 \%$.

TABELA 1 - Resultados sorológicos encontrados em Felis catus de diferentes cidades brasileiras e possíveis fatores associados à infecção pelo Toxoplasma gondii em cada população pesquisada.

\begin{tabular}{|c|c|c|}
\hline Região & (\%)Teste & Fatores associados à infecção \\
\hline $\begin{array}{c}\text { Porto Alegre - RS } \\
\text { (ARAUJO et al., 2003) }\end{array}$ & $37 \%(\mathrm{HAl})$ & Idade \\
\hline $\begin{array}{c}\text { Niterói - RJ } \\
\text { (NETTO et al., 2003) }\end{array}$ & $21,95 \%(\mathrm{HAl})$ & $\mathrm{N} / \mathrm{O}$ \\
\hline $\begin{array}{c}\text { Curitiba - PR } \\
\text { (VARGAS, 2006) }\end{array}$ & $17,2 \%(\mathrm{IFI})$ & Idade \\
\hline $\begin{array}{l}\text { Araçatuba - SP } \\
\text { (VIOL et al.) }\end{array}$ & $22,8 \%(\mathrm{HAl})$ & 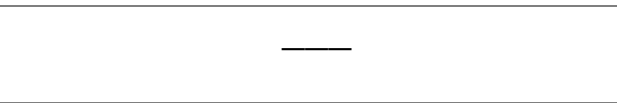 \\
\hline $\begin{array}{c}\text { Eldorado - MS } \\
\text { (MARQUES et al., 2009) }\end{array}$ & $57,14 \%(\mathrm{MAT})$ & $\mathrm{N} / \mathrm{O}$ \\
\hline $\begin{array}{l}\text { Porto Alegre - RS } \\
\text { (PINTO et al., 2009) }\end{array}$ & $37,9 \%(\mathrm{IFI})$ & Acesso à rua e idade \\
\hline $\begin{array}{c}\text { Lages - SC } \\
\text { (DALLA ROSA et al., 2010) }\end{array}$ & $14,33 \%(I F I)$ & Acesso à rua e idade \\
\hline $\begin{array}{c}\text { Curitiba - PR } \\
\text { (CRUZ MDE et al., 2011) }\end{array}$ & $16,3 \%(\mathrm{IFI})$ & $\mathrm{N} / \mathrm{O}$ \\
\hline $\begin{array}{c}\text { Niterói - RJ } \\
\text { (TEMOCHE, 2012) }\end{array}$ & $10,3 \%(\mathrm{HAl})$ & Alimentação \\
\hline $\begin{array}{c}\text { São Luís - MA } \\
\text { (BRAGA MDO et al., 2012) }\end{array}$ & $50,7 \%(\mathrm{IFI})$ & 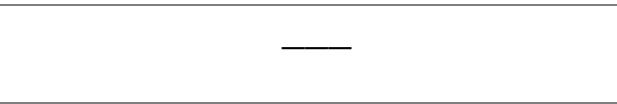 \\
\hline $\begin{array}{c}\text { Vitória - ES } \\
\text { (COVRE, 2014) }\end{array}$ & $15,2 \%(E L I S A)$ & Sexo \\
\hline $\begin{array}{c}\text { Rio de Janeiro } \\
\text { (BASTOS et al., 2014) }\end{array}$ & $5,6 \%(\mathrm{HAl})$ & $\mathrm{N} / \mathrm{O}$ \\
\hline
\end{tabular}

N/O: não observou relação estatística com nenhum fator associado à infecção pelo $T$. gondii. 
As razões para essas variações são muitas, uma delas deve-se às populações de aves e roedores na área, os quais podem estar contaminados com o T. gondii e serem predados, porém quando ocorre o controle destes animais e o fornecimento de ração, o que diminui a chance de contaminação por bradizoítos e taquizoítos, a prevalência em gatos tende a ser reduzida (DUBEY, 2010).

Estudos relatam que gatos mais velhos apresentam maior chance de se apresentarem positivos para a toxoplasmose (GARCIA et al., 1999), entretanto, alguns autores não encontraram diferença significativa entre as faixas etárias dos gatos positivos (NETTO et al., 2003; CRUZ MDE et al., 2011).

Em condições experimentais ideais, gatos podem eliminar oocistos após a ingestão de poucos bradizoítos por um período que varia de uma a três semanas, e acredita-se que a imunidade impossibilite a reeliminação de tal fase do protozoário (JONES et al., 2010). Contudo, estudos experimentais demonstraram que após imunossupressão com acetato de metilprednisolona (DUBEY et al., 1974), ou após um período de seis anos da infecção primária (DUBEY, 1995), ou devido a sucessivas infecções com diferentes cepas do T. gondii (ZULPO, 2014), tal fase de desenvolvimento do protozoário poderia ser lançada no ambiente novamente, porém, a reeliminação de oocistos na natureza ainda não foi comprovada.

Destaca-se que o período pré-patente da infecção depende da fase infecciosa do protozoário, para casos onde ingeriu-se os cistos tissulares o tempo de eliminação de oocistos será de três a dez dias, quando a ingestão for oocistos este intervalo passará a ser de 18 dias e no caso dos taquizoítos o mesmo será de 13 dias (DUBEY et al., 1998). Desta forma, os felídeos podem eliminar milhões de oocistos após a ingestão de qualquer uma das três fases do T. gondii (DUBEY, 2010).

A detecção de oocistos nas fezes de gatos é relativamente rara, pois a frequência é de aproximadamente $1 \%$ nos animais estudados (DUBEY, 1995). Sendo que, menos de $50 \%$ dos gatos lançam oocistos no ambiente após a ingestão de taquizoítos ou oocistos, ao passo que quase todos os hospedeiros definitivos os eliminam após a ingestão de cistos presentes nos tecidos. Isto demonstra que tal protozoário está adaptado a ser transmitido pelo carnivorismo em gatos, sendo a transmissão pelos oocistos esporulados mais eficiente nos hospedeiros intermediários, tanto mamíferos como aves (DUBEY, 2010).

Destaca-se que a veiculação de oocistos esporulados pode ocorrer pela água, solo e por vegetais crus e frutas. A inalação de aerossóis com partículas de poeira contendo essa fase de desenvolvimento também tem sido considerada como meio de transmissão (KIJLSTRA et al., 2008). A infecção induzida por oocistos em humanos é clinicamente mais grave do que infecções por cistos presentes na carne crua (JONES et al., 2010). Por isso, o impacto na epidemiologia da toxoplasmose deve ser melhor investigado, pois são suspeitos de estarem associados às altas soroprevalências em humanos (BAHIA-OLIVEIRA et al., 2003), pois, pela ingestão de um único oocisto os hospedeiros intermediários podem se contaminar (DUBEY, 2010).

Ressalta-se que o oocisto esporulado pode ser destruído quando submetido à temperatura de $60^{\circ} \mathrm{C}$ por um a dois minutos, mas, resiste à degradação física, química e sobrevive em ambientes adversos, o que proporciona elevada chances de perpetuação na natureza (DUBEY, 2010). Desta forma, a detecção de oocistos é importante para a vigilância epidemiológica e consequentemente para a Saúde Pública. Contudo, resultados sorológicos de gatos não identificam a eliminação dos oocistos, pois estes depois de infectados terão títulos de anticorpos 
detectáveis somente 14 a 21 dias após a infecção, sendo este o período em que os oocistos estarão sendo eliminados. Ou seja, durante o lançamento de oocistos no ambiente os níveis de anticorpos são baixos (CORNELISSEN et al., 2014).

Mesmo assim pesquisas epidemiológicas buscam fazer tal associação, entretanto os resultados sorológicos normalmente são superiores a detecção de oocistos, isso significa que a prevalência de excreção de oocistos nas fezes é muito menor do que a soroprevalência encontrada (tabela 2).

TABELA 2 - Resultados sorológicos encontrados em Felis catus positivos para o Toxoplasma gondii e a frequência de oocistos deste protozoário em suas fezes.

\begin{tabular}{|c|c|c|}
\hline Região & (\%)Teste & (\%) Diagnóstico de oocistos \\
\hline $\begin{array}{c}\text { Brasil } \\
\text { (PENA et al., 2006) }\end{array}$ & $35,4 \%(\mathrm{MAT})$ & $1,7 \%$ (Bioensaio) \\
\hline $\begin{array}{c}\text { Brasil } \\
\text { (VARGAS, 2006) }\end{array}$ & $17,2 \%(I F I)$ & 0,00\% (Microscopia) \\
\hline $\begin{array}{c}\text { Israel } \\
\text { (SALANT et al., 2007) }\end{array}$ & - & $9 \%(\mathrm{PCR})$ \\
\hline $\begin{array}{c}\text { EUA } \\
\text { (DABRITZ et al., 2007) }\end{array}$ & - & 0,9\% (Microscopia) \\
\hline $\begin{array}{c}\text { Caribe } \\
\text { (DUBEY, MOURA, et al., } \\
\text { 2009) }\end{array}$ & 73,9\%(MAT) & $0,00 \%$ (Bioensaio) \\
\hline $\begin{array}{c}\text { Suíça } \\
\text { (BERGER-SCHOCH et al., } \\
\text { 2011) }\end{array}$ & _ & $0,4 \%$ (PCR) \\
\hline $\begin{array}{c}\text { Canadá } \\
\text { (STOJANOVIC et al., 2011) }\end{array}$ & $29,8 \%($ MAT) & 1,3\% (Microscopia) \\
\hline $\begin{array}{c}\text { Brasil } \\
\text { (TEMOCHE, 2012) }\end{array}$ & $10,3 \%(\mathrm{HAl})$ & 0,00\% (Microscopia) \\
\hline $\begin{array}{c}\text { Peru } \\
\text { (TEMOCHE, 2012) }\end{array}$ & $11 \%(\mathrm{HAI})$ & 0,00\% (Microscopia) \\
\hline $\begin{array}{l}\text { Etiópia } \\
\text { (DUBEY, DARRINGTON, et } \\
\text { al., 2013) }\end{array}$ & $91,6 \%(\mathrm{MAT})$ & 19,4\% (Bioensaio) \\
\hline $\begin{array}{c}\text { EUA } \\
\text { (LILLY et al., 2013) }\end{array}$ & _ & $6 \%(\mathrm{PCR})$ \\
\hline $\begin{array}{c}\text { Brasil } \\
\text { (BASTOS et al., 2014) }\end{array}$ & $5,6 \%(\mathrm{HAl})$ & 0,00\% (Microscopia) \\
\hline $\begin{array}{c}\text { Portugal } \\
\text { (ESTEVES et al., 2014) }\end{array}$ & $20,5 \%(\mathrm{MAT})$ & $35,6 \%$ (PCR) \\
\hline
\end{tabular}

\section{SINAIS CLÍNICOS}

De acordo com o apresentado, anticorpos contra o T. Gondii podem ser detectados em gatos, contudo, por ser um hospedeiro definitivo raramente desenvolve a doença clínica e por isso são escassos o seu relatado (DUBEY, 2010). A razão pela qual alguns animais desenvolvem a toxoplasmose clínica não é totalmente compreendida, embora idade, infecções simultâneas, patogenicidade da 
cepa do protozoário e imunossupressão, sejam considerados fatores associados à doença clínica (DUBEY \& PROWELL, 2013).

Quando ocorre, a toxoplasmose é mais grave em gatos neonatais. No entanto, a enfermidade pode ocorrer de forma grave em gatos adultos (DUBEY \& PROWELL, 2013). Quando ocorre o desenvolvimento da enfermidade, diversos sinais clínicos são relatados como febre, diarreia, anorexia, dispneia e polipneia, ictericia, hepatite, pancreatite, alterações dermatológicas, doença ocular, podendo o animal vir a óbito em decorrência do agravamento dos sintomas (DUBEY, 2010).

\section{DIAGNÓSTICO}

Por não apresentar sintomas patognomônicos e por ser uma zoonose, o diagnóstico laboratorial da toxoplasmose tem grande importância para vigilância epidemiológica e Saúde Pública. Para diagnosticá-la, inicialmente usa-se a sorologia, que busca demonstrar níveis de anticorpos específicos ao $T$. gondii, sendo que os títulos se mantêm elevados durante meses a anos. O método sorológico é eficiente para indicar o contato com o protozoário e em qual fase da infecção este se encontra (MONTOYA, 2002).

Contudo, em gatos, durante o período de liberação de oocistos, os títulos de anticorpos são baixos (DUBEY et al., 2008), o que faz com que neste período a pesquisa sorológica tenha pouca validade em felídeos, devendo-se então associar os exames sorológicos a métodos de detecção de oocisto nas fezes.

\section{Diagnóstico sorológico}

Após a infecção pelo $T$. gondii inicia-se a soroconversão, sendo as imunoglobulinas $\mathrm{M}(\mathrm{IgM})$ as primeiras a se elevar, mas logo diminuem, chegando a títulos não detectáveis, passando o animal a ter as imunoglobulinas G (lgG) como proteção (VARGAS, 2006). Portanto, os estudos sorológicos devem detectar a IgM em gatos e associá-la ao período de eliminação de oocistos, pois estes estão relacionados à infecção recente, conhecida como aguda, enquanto a lgG é característica da fase crônica.

Assim, a pesquisa de diferentes classes de imunoglobulinas anti - $T$. gondii constitui o principal método laboratorial para o diagnóstico da doença em animais e humanos, pois permite a análise de perfis sorológicos, seja de infecção recente, em fase aguda, ou de infecção crônica (MONTOYA et al., 2004). Diversas técnicas sorológicas têm sido empregadas para diagnosticar a toxoplasmose em felídeos, como a aglutinação modificada (MAT), hemaglutinação indireta (HAI), reação de imunofluorescência indireta (IFI) e ensaio imunoenzimático (ELISA). Porém, o IFI possui como desvantagens a necessidade de um microscópio de fluorescência e conjungados específicos por espécie. Já o ELISA requer leitor para quantificar a cor da reação (DUBEY, 2010).

O MAT é um teste de aglutinação direta e simples, sendo amplamente utilizado para o diagnóstico da toxoplasmose em animais, porém o mesmo não faz diferenciação entre as imunoglobulinas de fase aguda ou crônica (DUBEY, 2010). Já - HAl apresenta elevada sensibilidade, simplicidade de execução, baixo custo (FIALHO et al., 2002) e é capaz de diferenciar IgG e IgM (TEMOCHE, 2012). Destaca-se que trabalho realizado por Silva (2008) demonstrou resultados iguais para detecção por HAl e MAT em felídeos silvestres. 


\section{Diagnóstico para a detecção de oocistos}

Em gatos, durante o período de liberação de oocistos os títulos de anticorpos são baixos, podendo não ser detectados pelos testes sorológicos, o que faz com que neste período a pesquisa sorológica possua pouca validade (DUBEY et al., 2008). Pode-se então realizar os exames coproparasitológicos seguido de microscopia. Contudo, os oocistos detectados serão os não esporulados, de difícil diferenciação visual entre oocistos de outras espécies de protozoários, como Besnoitia darlingi, B. wallacei, B. neotomofelis, B. oryctofelisi (DUBEY et al., 2010), Isospora felis, I. rivolta, Hammondia hammondi, Sarcocystis muris (figura 1), os quais podem estar presentes nas fezes do gato, mas não parasitam o homem (DUBEY, 2010).

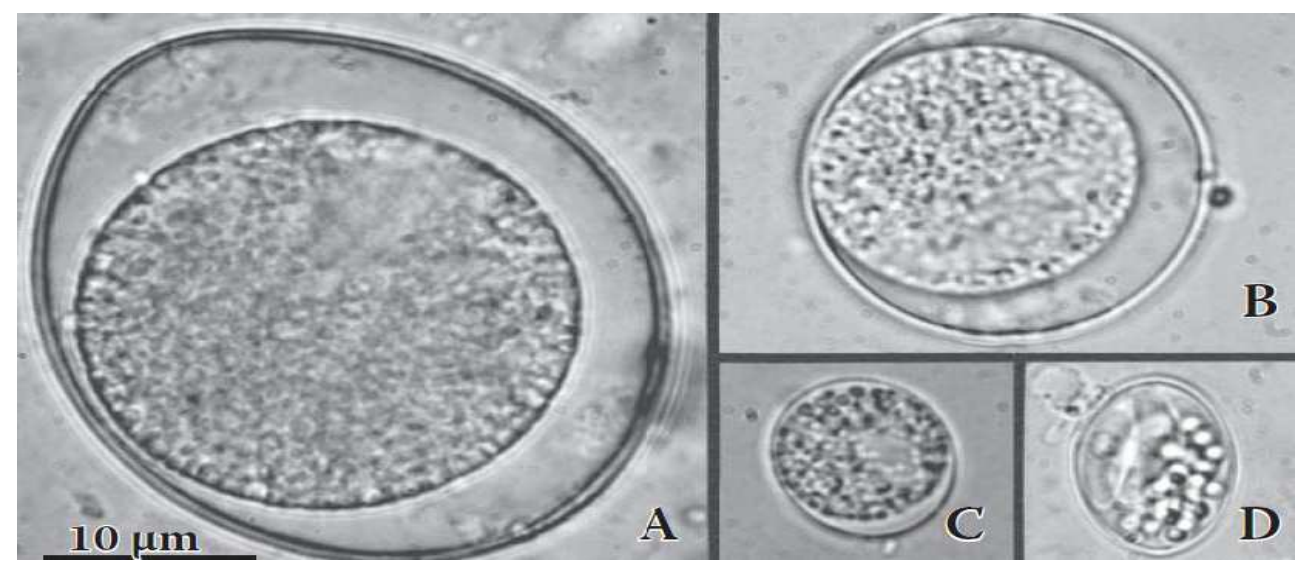

FIGURA 1 - Oocistos não esporulados de Isospora felis (A), I. rivolta (B) e Toxoplasma gondii (C), em comparação com esporocisto esporulado de Sarcocystis muris (D). Ampliação de $1600 \mathrm{x}$.

Fonte: Dubey (DUBEY, 2010)2010)

Outra opção é a diferenciação dos oocistos após a esporulação (DUBEY, 2010), todavia nesta situação há risco de infecção aos hospedeiros intermediários, desta forma tal procedimento só deve ser realizado em laboratórios altamente tecnificados. É possível também realizar o bioensaio em camundongos, que possui elevada sensibilidade e detecta até mesmo alguns oocistos viáveis de $T$. gondii (PENA et al., 2006; DUBEY, DARRINGTON, et al., 2013). No entanto, tal método representa risco biológico, sendo oneroso e podendo haver uma demora na apresentação de resultados satisfatórios. Tais características tornam este método impróprio para ser utlizado em grande escala (SALANT et al., 2010).

Em contrapartida, uma técnica desenvolvida por SALANT et al.,(2007) utilizando a reação em cadeia da polimerase (PCR), possibilitou maior segurança e correspondente sensibilidade quando comparado ao bioensaio em camundongos para a detecção de oocistos nas fezes de gatos (SALANT et al., 2010). A técnica baseia-se em flotação de material fecal em solução de Sheather, seguida de ruptura mecânica em nitrogênio líquido, posterior extração de DNA do extrato proveniente das fezes e por fim análise do material pela PCR convencional, o que proporciona a deteç̧ão de um a dois oocistos de $T$. gondii provenientes das fezes de gatos (SALANT et al., 2007). 


\section{CONTROLE E PREVENÇÃO DA TOXOPLASMOSE FELINA}

Buscando diminuir a contaminação dos gatos pelo $T$. gondii $\mathrm{e}$ consequente eliminação de oocistos no meio ambiente, mínimas ações podem resultar na prevenção da toxoplasmose, como por exemplo: tutores de gatos devem ser orientados a manterem os animais dentro de casa, sem acesso à rua; devem ensinar o animal a utilizar a caixa de areia, fornecer ração e água fresca e recolher as fezes diariamente. Devem ser promovidas orientações para a guarda responsável, bem como campanhas de castração, com o objetivo de reduzir a superpopulação e o número de gatos livres, os quais representam risco a Saúde Pública. Além, da orientação quanto a higiene rigorosa das mãos, principalmente após a jardinagem ou contato com o solo (DABRITZ et al., 2010).

\section{VÍRUS DA IMUNODEFICIÊNCIA FELINA}

Sabe-se que a infecção simultânea do $T$. gondii em felinos com outros patógenos, por exemplo, o vírus da imunodeficiência felina (FIV), pode pré dispor o desenvolvimento agudo da toxoplasmose (DUBEY, 2010). O FIV é um lentivirus da família Retroviridae que pode estabelecer infecção persistente em felídeos silvestres como também em gatos domésticos ( $F$. catus) (TEIXEIRA et al., 2007). Devido ao seu tropismo por células linfoides do sistema imune, tal agente infeccioso pode resultar em desregulação da imunidade celular, por isso está associado às síndromes de imunossupressão (ALVES et al., 2012).

É reconhecido como modelo excelente para estudos do vírus da imunodeficiência humana (HIV) e da AIDS, resultante da infecção como o vírus da imunodeficiência humana do tipo HIV-1. Assim, sabe-se que aquele causa em gatos uma enfermidade bastante similar à observada em paciente com AIDS (TEIXEIRA et al., 2007). Como outros retrovírus, sua estrutura genômica é constituída, além de genes acessórios, por três genes principias: o gag, que codifica a proteína de capsídeo p-24; o pol, responsável por codificar proteases, integrases e proteínas de transcriptase reversa e o env que codifica a glicoproteína viral (gp120 ) e a proteína transmembranar (gp41) (ALVES et al., 2012).

Estudos prévios baseados na diversidade genética do gene env demonstraram a ocorrência de cinco subtipos diferentes do vírus, designados de $\mathrm{A}$, $B, C, D$ e E, sendo que tais cepas estão presentes em felídeos por todo mundo (LARA et al., 2007). No Brasil, pouco se conhece sobre a diversidade genética do FIV, porém já foi isolado e identificado o subtipo B (TEIXEIRA, 2010; SILVA et al., 2014), o qual apresenta baixa virulência (LARA et al., 2007).

\section{EPIDEMIOLOGIA}

A distribuição do FIV é cosmopolita, sendo considerado o patógeno mais comum entre as doenças infecciosas de gatos domésticos, pequenos felídeos e gatos silvestres. Está associado à alta densidade populacional, além de aumentar o risco a infecções oportunistas, por ser imunossupressor (ALVES et al., 2012). A forma primária de transmissão natural do FIV é por meio da saliva em mordidas infligidas por animais infectados. A transmissão intrauterina, perinatal, pelo colostro, leite, ou pelo sêmen de machos soropositivos também pode ocorrer (ALVES et al., 2011). Desta forma, o FIV é transmitido principalmente pela mordedura, assim animais machos não castrados e que se envolvem em brigas possuem maiores chances de se infectarem com o vírus (TEIXEIRA et al., 2007).

Altas taxas de infecção são encontradas em gatos adultos com livre acesso à rua, os quais frequentemente apresentam comportamento agressivo 
(TEIXEIRA et al., 2007). Desta forma, o FIV está associado principalmente à vida livre e mordeduras decorrentes de lutas por território, por conseguinte, a transmissão é baixa em gatos socialmente bem adaptados (ALVES et al., 2012).

O agente apresenta prevalência variada segundo as regiões geográficas e fatores associados à infecção como: gênero masculino, idade adulta, acesso ao exterior (HARTMANN, 2011), comportamento agressivo e animais doentes (TEIXEIRA et al., 2007), os quais são mais propensos a apresentaram-se positivos para tal enfermidade. Portanto, diferentes prevalências são encontradas pelo mundo, variando em estudos de 1 a $44 \%$ (SILVA et al., 2014), porém até o momento na América do Sul o maior resultado registrado foi de 34,6\%, encontrado na Argentina (TEIXEIRA et al., 2012). No Brasil, poucos são os grupos científicos que estudam tal patógeno e quando ocorre, a maioria não avalia os fatores associados à infecção pelo FIV, sendo que as pesquisas concentram-se na região sul e sudeste e somente um trabalho realizado no Distrito Federal foi encontrado na literatura consultada (tabela 3).

TABELA 3 - Resultados encontrados em Felis catus de diferentes regiões do Brasil, com variados testes e fatores associados à infecção pelo vírus da imunodeficiência.

\begin{tabular}{|c|c|c|}
\hline Estado & Resultado (\%) & $\begin{array}{l}\text { Fatores associados à } \\
\text { infecção }\end{array}$ \\
\hline $\begin{array}{c}\text { Minas Gerais } \\
\text { (TEIXEIRA et al., 2007) }\end{array}$ & PCR (4,14\%) & - \\
\hline $\begin{array}{c}\text { Minas Gerais } \\
\text { (RIVETTI JR, 2006) }\end{array}$ & PCR $(9,4 \%)$ & - \\
\hline $\begin{array}{l}\text { Rio Grande do Sul } \\
\text { (SILVA, 2007) }\end{array}$ & PCR + ELISA (21,5\%) & Acesso à rua \\
\hline $\begin{array}{l}\text { Minas Gerais } \\
\text { (ALVES, 2010) }\end{array}$ & $P C R+E L I S A(3,85 \%)$ & $\mathrm{N} / \mathrm{O}$ \\
\hline $\begin{array}{l}\text { São Paulo } \\
\text { (SOBRINHO et al., } \\
\text { 2011) }\end{array}$ & ELISA (5,63\%) & Idade e macho \\
\hline $\begin{array}{c}\text { Paraná } \\
\text { (ROSA et al., 2011) }\end{array}$ & ELISA (3\%) & - \\
\hline $\begin{array}{c}\text { Distrito Federal } \\
\text { (MARTINS et al., 2012) }\end{array}$ & ELISA (2,77\%) & - \\
\hline $\begin{array}{c}\text { Paraná } \\
\text { (MONTAÑO et al., } \\
\text { 2013) }\end{array}$ & ELISA (8,33\%) & - \\
\hline $\begin{array}{l}\text { Rio Grande do Sul } \\
\text { (SILVA et al., 2014) }\end{array}$ & PCR (15,7\%) & Idade \\
\hline $\begin{array}{l}\text { Rio de Janeiro } \\
\text { (CARNEIRO et al., } \\
\text { 2014) }\end{array}$ & PCR + ELISA $(4,47 \%)$ & - \\
\hline
\end{tabular}

N/O: não observou relação estatística com nenhum fator associado à infecção pelo vírus da imunodeficiência felina.

\section{PATOGENIA E SINAIS CLÍNICOS}

Quando invade o organismo o vírus infecta principalmente linfócitos $T$ CD4 e CD8, mas também pode se replicar em linfócitos $B$ e macrófagos. ENCICLOPÉDIA BIOSFERA, Centro Científico Conhecer - Goiânia, v.11 n.22; p.2003 2015 
Consequentemente, há a diminuição dos linfócitos T CD4, ao mesmo tempo, os linfócitos T CD8 aumentam gradativamente, resultando na inversão na taxa de linfócitos T CD4 / T CD8, comprometendo a resposta imune do animal (RAJÃO et al., 1999). Desta forma, a infecção é caracterizada pelo declínio progressivo de células T CD4 circulantes, o que propicia a imunodeficiência, aumentando o risco de desenvolvimento de infecções oportunistas. Mas, o próprio vírus não causa sinais clínicos graves, e os gatos infectados podem viver por muitos anos (HARTMANN, 2011).

Clinicamente, a síndrome da imunodeficiência adquirida dos felinos pode ser caracterizada por cinco estágios da doença: aguda, com doenças passageiras, apresentando neutropenia, linfoadenopatia e febre; assintomática, podendo não ocorrer, sendo que a infecção pode permanecer inaparente por períodos prolongados; linfadenopatia persistente generalizada, caracterizada pelo aumento de nódulos linfáticos e vagos sinais clínicos, como febre recorrente, mas sem infecções graves (ALVES, 2010).

A quarta fase é o complexo relacionado com AIDS (CRA), conjunto de sintomas e sinais inespecíficos de intensidade variável, além de processos oportunistas de menor gravidade. Pode durar meses a anos, com 0 animal apresentando linfoadenopatia generalizada, febre recorrente, apatia, leucopenia, anemia, anorexia, perda de peso e estomatite crônica (figura 2). Desordens neurológicas, renais e neoplasias são menos frequentes. A maioria dos animais em CRA progride para a quinta fase, conhecida como AIDS felina, na qual ocorrem os sintomas da ARC mais infecções oportunistas, neoplasias e anormalidades neurológicas (ALVES, 2010).

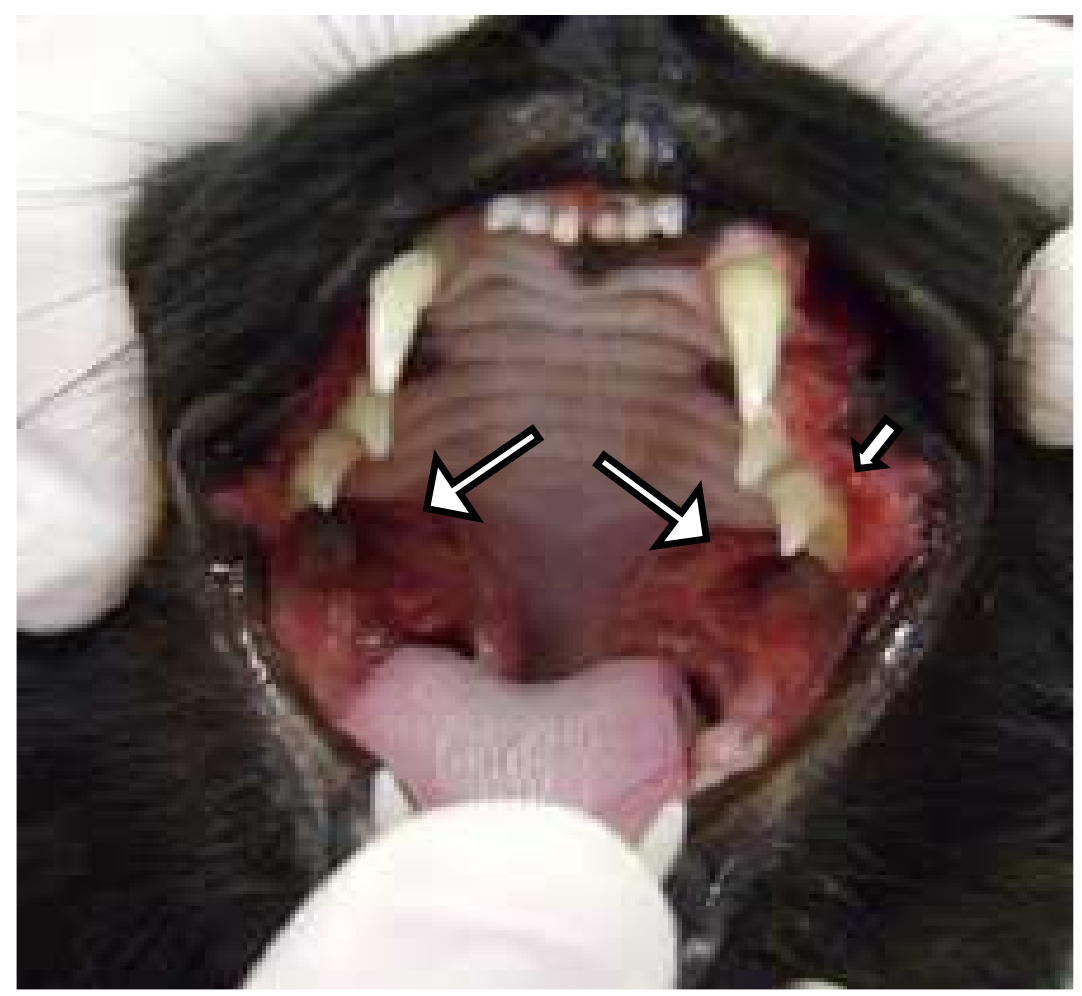

FIGURA 2 - Gengivite (seta pequena) e estomatite (setas maiores) em gato positivo para o vírus da imunodeficiência felina.

Fonte: adaptado de Alves \& Reis (2012). 


\section{DIAGNÓSTICO}

A imunodeficiência provocada pelo FIV não cursa com sintomas clínicos patognomônicos. Portanto, o diagnóstico definitivo deve ser realizado em conjunto com exames complementares como a detecção direta, com isolamento viral e testes moleculares como a PCR, e métodos de detecção indireta, testes imunológicos para detecção de anticorpos como 0 ensaio imunoenzimático (ELISA), imunocromatografia e o Western blot. Este último é considerado padrão-ouro para o diagnóstico sorológico do vírus, porém não é utilizado na rotina clínica (TEIXEIRA, 2010).

Em contraste com a maioria das viroses, a simples demonstração de anticorpos anti- FIV no soro pode ser considerada adequada para o diagnóstico de uma infecção, já que ocorre a persistência da infecção viral, mesmo diante de resposta imunológica adequada do hospedeiro (TEIXEIRA, 2010). Desta forma, os testes utilizados na rotina clínica, como o ELISA e ou a imunocromatografia, se baseiam na detecção de anticorpos que reconhecem as proteínas estruturais do vírus (como a p-24 e p-15) e uma das glicoproteínas do envelope viral, gp-41 (TEIXEIRA, 2010). No entanto, em um estudo realizado por Alves (ALVES, 2010) foi padronizado o teste r-p24 ELISA a qual demonstrou sensível, específica e podendo assim ser aplicada para o diagnóstico de rotina e ou em pesquisa da infecção pelo vírus, pois apresenta baixo custo quando comparado aos testes comerciais.

Os resultados das diversas técnicas complementares para o diagnóstico do FIV devem ser interpretados cuidadosamente, pois podem ocorrer falsospositivos, independentemente do método sorológico utilizado, pois geralmente os testes são altamente sensíveis. Assim, quando encontrado um resultado positivo em um animal com baixo risco de infecção, por exemplo, gato sem histórico de acesso a rua, o resultado deve ser confirmado por novos testes. Resultado positivo em um gato pertencente a um grupo de risco (gato macho, adulto, com acesso à rua) tem um valor preditivo positivo alto. Resultados falsos negativos podem ser encontrados na fase terminal da doença em animais com baixos títulos de anticorpos (TEIXEIRA, 2010).

A presença de anticorpos maternos em filhotes nascidos de mães positivas ao FIV pode resultar em testes positivos, portanto, os exames devem ser realizados após 16 semanas de idade. A reação em cadeia da polimerase, PCR, neste caso constitui-se em uma excelente ferramenta, levando-se em consideração a necessidade de realizar o teste também na mãe para a identificação correta da cepa infectante envolvida (TEIXEIRA, 2010).

\section{CONTROLE E PREVENÇÃO DO VÍRUS DA IMUNODEFICIÊNCIA FELINA EM GATOS DOMÉSTICOS}

O FIV não sobrevive por muito tempo fora do hospedeiro e é facilmente inativado por desinfetantes, aquecimento e secagem, desta forma deve-se manter a adequada higiene do ambiente dos gatos infectados. No entanto, a identificação e a segregação de gatos contaminandos é a forma mais eficaz de prevenir novas infecções (HARTMANN, 2011). Assim, é importante isolar o animal diagnosticado com o FIV e mantê-lo em bom estado de saúde, com diagnóstico rápido e preciso de quaisquer doenças secundárias. Gatos positivos devem ser castrados para reduzir agressividade e o risco de contaminação durante a luta e cópula, pois no Brasil ainda não existem vacinas para tal vírus (ALVES et al., 2012).

Ressalta-se que gatos positivos não devem ser sacrificados, pois estes podem ter uma longa vida. No entanto, devem ser levados regularmente ao 
veterinário para realização de check up. Mas, a eutanásia deve ser considerada quando problemas clínicos estão ligados à fase avançada da infecção (ALVES et al., 2012).

\section{GATOS COINFECTADOS PELO Toxoplasma gondii E PELO VÍRUS DA IMUNODEFICIÊNCIA FELINA}

A toxoplasmose em conjunto com a infecção pelo FIV, que é uma das mais importantes retroviroses dentre a clínica de felinos, pode apresentar manifestações clínicas graves (RIVETTI JR et al., 2008). Isso devido ao declínio progressivo de células T CD4 circulantes, o que propicia a imunodeficiência, aumentando o risco de desenvolvimento de infecções oportunistas, como a toxoplasmose aguda em gatos domésticos (ZANUTTO, 2005).

Em geral, a infecção pelo FIV pode favorecer a proliferação do $T$. gondii em felídeos. Todavia, estudo realizado por Lin et al. ,(LIN et al., 1992) demonstrou que o estabelecimento da toxoplasmose pode aumentar a imunodeficiência induzida pelo vírus e provocar uma progressão da doença mais rápida do que a infecção provocada somente pelo FIV. Desta forma, um número significante de gatos com suspeita clínica de toxoplasmose pode estar infectado concomitantemente pelo FIV. Contudo, não se sabe qual patógeno foi responsável pela infecção primária, pois, o $T$. gondii pode ser um oportunista infectando o animal após a contaminação com o FIV, ou o animal infectado de primeira com o protozoário, após infecção com o vírus pode desencadear a forma generalizada da toxoplasmose (DUBEY, 2010).

Ressalta-se que felinos duplamente infectados por tais patógenos apresentam soroprevalência mais elevada para toxoplasmose (DUBEY, 2010). Pelo fato da imunossupressão induzida levar a reeliminação de oocistos no ambiente (DUBEY et al., 1974), acredita-se que a coinfecção pelo FIV possa reativar o protozoário e consequentemente levar a um segundo período de derramamento daquela forma infectante no meio-ambiente (AKHTARDANESH et al., 2010), assim a interação desses agentes pode resultar na reativação da toxoplasmose nos felídeos (RIVETTI JR et al., 2008).

A infecção pelo FIV pode levar os hospedeiros definitivos e soropositivos para o $T$. gondii, os quais não representavam mais risco a Saúde Pública em relação a toxoplasmose, a atuarem novamente como eventuais fontes de infecção. Entretanto, são poucos os trabalhos que buscam determinar a ocorrência simultânea destes dois agentes infecciosos, como pode ser observado na tabela 4, bem como a eliminação de oocistos do protozoário nas fezes dos animais coinfectados.

Somente um trabalho foi encontrado na literatura com o objetivo de demonstrar a ocorrência das duas infecções e a possível eliminação de oocistos no ambiente, porém o único animal deste estudo em que foi identificado a presença do oocisto nas fezes foi negativo para o FIV (STOJANOVIC et al., 2011). Assim, destaca-se que a maioria das pesquisas encontradas não analisaram as amostras fecais dos gatos, o que impossibilitou obter informações sobre o efeito dessa coinfecção e o lançamento de oocistos no ambiente. 
TABELA 4 - Resultados encontrados para o Toxoplasma gondii e o vírus da imunodeficiência em Felis catus de diferentes regiões do mundo, com possível coinfecção entre os patógenos e a eliminação de oocistos nas fezes dos animais avaliados.

\begin{tabular}{|c|c|c|c|c|}
\hline Região & (\%) T. gondii & (\%) FIV & $\begin{array}{l}\text { (\%) T. gondii } \\
\text { +FIV }\end{array}$ & $\begin{array}{c}(\%) \\
\text { Oocistos }\end{array}$ \\
\hline $\begin{array}{c}\text { Bélgica } \\
\text { (DORNY et al., 2002) }\end{array}$ & 70,2\%(MAT) & $\begin{array}{c}\text { ELISA } \\
(11,3 \%)\end{array}$ & $9,5 \%$ & - \\
\hline $\begin{array}{c}\text { Brasil } \\
\text { (RIVETTI JR, 2006) }\end{array}$ & $50 \%(\mathrm{IFI})$ & $\begin{array}{l}\text { PCR } \\
(9,4 \%)\end{array}$ & $2,2 \%$ & - \\
\hline $\begin{array}{c}\text { Caribe } \\
\text { (DUBEY, LAPPIN, et } \\
\text { al., 2009) }\end{array}$ & $30,6 \%(\mathrm{MAT})$ & $\begin{array}{c}\text { ELISA } \\
(15,9 \%)\end{array}$ & - & - \\
\hline $\begin{array}{c}\text { Irã } \\
\text { (AKHTARDANESH et } \\
\text { al., 2010) }\end{array}$ & $32,1 \%(\mathrm{MAT})$ & $\begin{array}{c}\text { ELISA } \\
(19,2 \%)\end{array}$ & $25,71 \%$ & - \\
\hline $\begin{array}{c}\text { Canadá } \\
\text { (STOJANOVIC et al., } \\
\text { 2011) }\end{array}$ & $29,8 \%($ MAT) & $\begin{array}{l}\text { ELISA } \\
(5,2 \%)\end{array}$ & - & 1,3\%(Micro) \\
\hline $\begin{array}{c}\text { Brasil } \\
\text { (SOBRINHO et al., } \\
\text { 2012) }\end{array}$ & $20,32 \%(\mathrm{IFI})$ & $\begin{array}{c}\text { ELISA } \\
(5,63 \%)\end{array}$ & $2,79 \%$ & - \\
\hline $\begin{array}{c}\text { Tailândia } \\
\text { (SUKHUMAVASI et } \\
\text { al., 2012) }\end{array}$ & $10,1 \%(\mathrm{MAT})$ & $\begin{array}{l}\text { ELISA } \\
(20,1 \%)\end{array}$ & $3,2 \%$ & - \\
\hline $\begin{array}{c}\text { Etiópia } \\
\text { (TIAO et al., 2013) }\end{array}$ & $85,4 \%(\mathrm{MAT})$ & N/P & 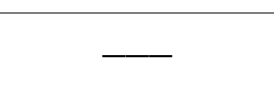 & - \\
\hline
\end{tabular}

Micro=microscopia.

$\mathrm{N} / \mathrm{P}=\mathrm{Não}$ encontrou gatos soropositivos para o vírus da imunodeficiência felina.

\section{CONSIDERAÇÕES FINAIS}

Por meio desta revisão, constatou-se que tanto o T. gondii como o FIV apresentam distribuição cosmopolita e podem ser detectados em diversas regiões do Brasil. São importantes patógenos na clínica de felinos, pois podem levar ao desenvolvimento de sintomas clínicos variados, podendo ter o óbito como consequência. Considerando que normalmente o gato não desenvolve a toxoplasmose clínica, quando a detecção desta deve ser considerada a coinfecção com outros patógenos, como o FIV, por exemplo.

Deve ser destacado que a prevalência para anticorpos anti- T. gondii em algumas regiões do mundo é elevada, entretanto a detecção de oocistos deste protozoário nas fezes do $F$. catus é baixa, independentemente do método utilizado. O número de animais positivos para o FIV na maioria das vezes é baixo. Quando positivos para tal retrovírus, o gato apresenta grande importância na clínica veterinária e na Saúde Pública, pois sendo um agente imunossupressor diversas doenças oportunistas podem acometer tais indivíduos, além de que os positivos são responsáveis pela manutenção da infecção na região.

Por fim, ressalta-se que gatos adultos com acesso à rua apresentam maiores chances de se infectarem com tais patógenos, desta forma medidas de controle e prevenção devem se concentrar na orientação e aplicação da guarda ENCICLOPÉDIA BIOSFERA, Centro Científico Conhecer - Goiânia, v.11 n.22; p.2007 
responsável buscando restringir o acesso à rua destes animais, bem como a realização da castração, objetivando-se o controle populacional do F. catus, principalmente nos grandes centros urbanos.

\section{REFERÊNCIAS}

AKHTARDANESH, B.; ZIAALI, N.; SHARIFI, H.; REZAEI, S. Feline immunodeficiency virus, feline leukemia virus and Toxoplasma gondii in stray and household cats in Kerman-Iran: seroprevalence and correlation with clinical and laboratory findings. Research in veterinary science, v. 89, n. 2, p. 306-310, 2010.

AL-KAPPANY, Y. M.; LAPPIN, M. R.; KWOK, O. C.; ABU-ELWAFA, S. A.; HILALI, M.; DUBEY, J. P. Seroprevalence of Toxoplasma gondii and concurrent Bartonella spp., feline immunodeficiency virus, feline leukemia virus, and Dirofilaria immitis infections in Egyptian cats. The Journal of parasitology, v. 97, n. 2, p. 256-258, 2011.

F. Padronização de um ELISA indireto para o diagnóstico da imunodeficiência felina a vírus 2010. 32 (Tese). Programa de Pós-graduação da Escola de Veterinária, Universidade Federal de Minas Gerais, Belo Horizonte.

ALVES, F.; REIS, J. K. P.; VIEIRA, F. O.; DEL PUERTO, H. L.; BRAZ, G. F.; RAJÃO, D. S.; MARTINS, A. S.; MAZUR, C.; LEITE, R. C. Retroviroses em felinos domésticos: um problema de saúde pública. NBC Research Biochemicals, v. 1, n. 2, 2011.

ALVES, F.; REIS, J. K. P. Feline Immunodeficiency. Immunodeficiency Intech, 2012. ISSN 978-953-51-0791-0. Disponível em: < http://www.intechopen.com/books/immunodeficiency/feline-immunodeficiency >. Acesso em: agust 7th, 2014.

ARAUJO, F. A. P.; SILVA, N. R. S.; OLICHESKI, A. T.; BECK, C.; RODRIGUES, R. J. D.; FIALHO, C. G. Anticorpos para Toxoplasma gondii em soro de gatos internados no Hospital de Clinicas Veterinárias da UFRGS, Porto Alegre, RS, Brasil, detectados através da técnica de hemaglutinação indireta. Acta Scientiae Veterinariae, v. 31, n. 2, p. 89-92, 2003.

BAHIA-OLIVEIRA, L. M.; JONES, J. L.; AZEVEDO-SILVA, J.; ALVES, C. C.; OREFICE, F.; ADDISS, D. G. Highly endemic, waterborne toxoplasmosis in north Rio de Janeiro state, Brazil. Emerging Infectious Diseases, v. 9, n. 1, p. 55-62, 2003.

BASTOS, B. F.; BRENER, B.; GERSHONY, L.; WILLI, L.; LABARTHE, N.; PEREIRA, C.; MENDES-DE-ALMEIDA, F. Seroprevalence of Toxoplasma gondii (Nicole \& Manceaux, 1909) and retroviral status of client-owned pet cats (Felis catus, Linnaeus, 1758) in Rio de Janeiro, Brazil. Revista do Instituto de Medicina Tropical de São Paulo, v. 56, n. 3, p. 201-203, 2014.

BERGER-SCHOCH, A. E.; HERRMANN, D. C.; SCHARES, G.; MULLER, N.; BERNET, D.; GOTTSTEIN, B.; FREY, C. F. Prevalence and genotypes of Toxoplasma gondii in feline faeces (oocysts) and meat from sheep, cattle and pigs in Switzerland. Veterinary Parasitology, v. 177, n. 3-4, p. 290-297, 2011. 
BRAGA MDO, S.; ANDRE, M. R.; JUSI, M. M.; FRESCHI, C. R.; TEIXEIRA, M. C.; MACHADO, R. Z. Occurrence of anti-Toxoplasma gondii and anti-Neospora caninum antibodies in cats with outdoor access in Sao Luis, Maranhao, Brazil. Revista Brasileira de Parasitologia Veterinária, v. 21, n. 2, p. 107-111, 2012.

CARNEIRO, A. L.; MEDEIROS, S.; DIAS, C. G.; CARIDADE, A. Ocorrência dos Vírus da Imunodeficiência e da Leucemia Felina no Rio de Janeiro Avaliada Através da Sorologia e da PCR em Tempo Real. 13a edição da Pet South America - Feira Internacional de Produtos e Serviços para a Linha Pet e Veterinária., 2014. Disponível em:

http://www.petsa.com.br/uploads/trabalhos2014/0140231_1_000003.pdf >. Acesso em: july 7th, 2015.

CORNELISSEN, J. B.; VAN DER GIESSEN, J. W.; TAKUMI, K.; TEUNIS, P. F.; WISSELINK, $\mathrm{H}$. J. An experimental Toxoplasma gondii dose response challenge model to study therapeutic or vaccine efficacy in cats. PLoS One, v. 9, n. 9, p. e104740, 2014.

COVRE, K. C. Frequência de resultados positivos para Toxoplasma gondii em exames sorológicos realizados em cães e gatos na região metropolitana de Vitória, Espírito Santo, Brasil 2014. 68 (Dissertação). Pós-Graduação em Doenças Infecciosas do Centro de Ciências da Saúde, Universidade Federal do Espírito Santo, Vitória -ES.

CRUZ MDE, A.; ULLMANN, L. S.; MONTANO, P. Y.; HOFFMANN, J. L.; LANGONI, H.; BIONDO, A. W. Seroprevalence of Toxoplasma gondii infection in cats from Curitiba, Parana, Brazil. Revista Brasileira de Parasitologia Veterinária, v. 20, n. 3, p. 256-258, 2011.

DABRITZ, H. A.; MILLER, M. A.; ATWILL, E. R.; GARDNER, I. A.; LEUTENEGGER, C. M.; MELLI, A. C.; CONRAD, P. A. Detection of Toxoplasma gondii-like oocysts in cat feces and estimates of the environmental oocyst burden. Journal of the American Veterinary Medical Association, v. 231, n. 11, p. 1676-1684, 2007.

DABRITZ, H. A.; CONRAD, P. A. Cats and Toxoplasma: implications for public health. Zoonoses Public Health, v. 57, n. 1, p. 34-52, 2010.

DALLA ROSA, L.; MOURA, A. B.; TREVISANI, N.; MEDEIROS, A. P.; SARTOR, A. A.; SOUZA, A. P.; BELLATO, V. Toxoplasma gondii antibodies on domiciled cats from Lages municipality, Santa Catarina State, Brazil. Revista Brasileira de Parasitologia Veterinária, v. 19, n. 4, p. 268-269, 2010.

DORNY, P.; SPEYBROECK, N.; VERSTRAETE, S.; BAEKE, M.; DE BECKER, A.; BERKVENS, D.; VERCRUYSSE, J. Serological survey of Toxoplasma gondii, feline immunodeficiency virus and feline leukaemia virus in urban stray cats in Belgium. Veterinary Record v. 151, n. 21, p. 626-629, 2002.

DUBEY, J. P.; FRENKEL, J. K. Immunity to Feline Toxoplasmosis: Modification by Administration of Corticosteroids. Veterinary Pathology, v. 11, p. 350-379 1974.

DUBEY, J. P. Duration of immunity to shedding of Toxoplasma gondii oocysts by cats. The Journal of parasitology, v. 81, n. 3, p. 410-415, 1995. 
DUBEY, J. P.; LINDSAY, D. S.; SPEER, C. A. Structures of Toxoplasma gondii tachyzoites, bradyzoites, and sporozoites and biology and development of tissue cysts. Clinical Microbiology Reviews, v. 11, n. 2, p. 267-299, 1998.

DUBEY, J. P. The history of Toxoplasma gondii--the first 100 years. Journal of Eukaryotic Microbiology, v. 55, n. 6, p. 467-475, 2008.

DUBEY, J. P.; JONES, J. L. Toxoplasma gondii infection in humans and animals in the United States. International journal for parasitology, v. 38, n. 11, p. 12571278, 2008.

DUBEY, J. P.; LAPPIN, M. R.; KWOK, O. C.; MOFYA, S.; CHIKWETO, A.; BAFFA, A.; DOHERTY, D.; SHAKERI, J.; MACPHERSON, C. N.; SHARMA, R. N. Seroprevalence of Toxoplasma gondii and concurrent Bartonella spp., feline immunodeficiency virus, and feline leukemia virus infections in cats from Grenada, West Indies. The Journal of parasitology, v. 95, n. 5, p. 1129-1133, 2009.

DUBEY, J. P.; MOURA, L.; MAJUMDAR, D.; SUNDAR, N.; VELMURUGAN, G. V.; KWOK, O. C.; KELLY, P.; KRECEK, R. C.; SU, C. Isolation and characterization of viable Toxoplasma gondii isolates revealed possible high frequency of mixed infection in feral cats (Felis domesticus) from St Kitts, West Indies. Parasitology, v. 136, n. 6, p. 589-594, 2009.

DUBEY, J. P. Toxoplasmosis of animals and humans. 2. Boca Raton: CRC Press, 2010. 338.

DUBEY, J. P.; YABSLEY, M. J. Besnoitia neotomofelis n. sp. (Protozoa: Apicomplexa) from the southern plains woodrat (Neotoma micropus). Parasitology, v. 137, n. 12, p. 1731-1747, 2010.

DUBEY, J. P.; LAGO, E. G.; GENNARI, S. M.; SU, C.; JONES, J. L. Toxoplasmosis in humans and animals in Brazil: high prevalence, high burden of disease, and epidemiology. Parasitology, v. 139, n. 11, p. 1375-1424, 2012.

DUBEY, J. P.; DARRINGTON, C.; TIAO, N.; FERREIRA, L. R.; CHOUDHARY, S.; MOLLA, B.; SAVILLE, W. J.; TILAHUN, G.; KWOK, O. C.; GEBREYES, W. A. Isolation of viable Toxoplasma gondii from tissues and feces of cats from Addis Ababa, Ethiopia. The Journal of parasitology, v. 99, n. 1, p. 56-58, 2013.

DUBEY, J. P.; PROWELL, M. Ante-mortem diagnosis, diarrhea, oocyst shedding, treatment, isolation, and genetic typing of Toxoplasma gondii associated with clinical toxoplasmosis in a naturally infected cat. The Journal of parasitology, v. 99, n. 1, p. 158-160, 2013.

ESTEVES, F.; AGUIAR, D.; ROSADO, J.; COSTA, M. L.; DE SOUSA, B.; ANTUNES, F.; MATOS, O. Toxoplasma gondii prevalence in cats from Lisbon and in pigs from centre and south of Portugal. Veterinary Parasitology, v. 200, n. 1-2, p. 812, 2014.

FIALHO, C. G.; ARAÚJO, F. A. P. Comparação entre os testes de imunofluorescência indireta e hemaglutinação indireta para a detecção de anticorpos anti-Toxoplasma gondii em soros de suínos. Acta Scientiae Veterinariae, v. 30, n. 3, p. 185- 189, 2002. 
GARCIA, J. L. I.; NAVARRO, T.; OGAWA, L.; DE OLIVEIRA, R. C. Soroepidemiologia da toxoplasmose em gatos e cães de propriedades rurais do município de Jaguapitã, estado do Paraná, Brasil. Ciência Rural, v. 29, n. 1, p. 99104, 1999.

HARTMANN, K. Clinical aspects of feline immunodeficiency and feline leukemia virus infection. Veterinary Immunology and Immunopathology, v. 143, n. 3-4, p. 190201, 2011.

IBGE. Pesquisa nacional de saúde - 2013 - Acesso e utilização dos serviços de saúde, acidentes e violências - Brasil, grandes regiões e unidades da federação. Rio de Janeiro: IBGE, 2015.

JONES, J. L.; DUBEY, J. P. Waterborne toxoplasmosis - Recent developments. Experimental Parasitology, v. 124, n. 1, p. 10-25, 2010.

KIJLSTRA, A.; JONGERT, E. Control of the risk of human toxoplasmosis transmitted by meat. International journal for parasitology, v. 38, n. 12, p. 1359-1370, 2008.

LARA, V. M.; TANIWAKI, S. A.; ARAÚJO JR, J. P. Caracterização filogenética de amostras do vírus da imunodeficiência felina (FIV) do Estado de São Paulo. Pesquisa Veterinária Brasileira, v. 27, n. 11, p. 467-470, 2007.

LILLY, E. L.; WORTHAM, C. D. High prevalence of Toxoplasma gondii oocyst shedding in stray and pet cats (Felis catus) in Virginia, United States. Parasites \& Vectors, v. 6, p. 266, 2013.

LIN, D. S.; BOWMAN, D. D.; JACOBSON, R. H. Immunological changes in cats with concurrent Toxoplasma gondii and feline immunodeficiency virus infections. Journal of Clinical Microbiology, v. 30, n. 1, p. 17-24, 1992.

LOPES, F. M.; MITSUKA-BREGANO, R.; GONCALVES, D. D.; FREIRE, R. L.; KARIGYO, C. J.; WEDY, G. F.; MATSUO, T.; REICHE, E. M.; MORIMOTO, H. K.; CAPOBIANGO, J. D.; INOUE, I. T.; GARCIA, J. L.; NAVARRO, I. T. Factors associated with seropositivity for anti-Toxoplasma gondii antibodies in pregnant women of Londrina, Parana, Brazil. Memórias do Instituto Oswaldo Cruz, v. 104, n. 2, p. 378-382, 2009.

MARQUES, J. M.; ISBRECHT, F. B.; LUCAS, T. M.; GUERRA, I. M. P.; DALMOLIN, A.; SILVA, R. C.; LANGONI, H.; SILVA, A. V. Detecção de anticorpos antiToxoplasma gondii em animais de uma comunidade rural do Mato Grosso do Sul, Brasil. Semina-Ciencias Agrarias, v. 30, n. 4, p. 889-898, 2009.

MARTINS, E. S.; TOGNOLI, G. K.; IILHA, P. H. O.; MAZZOTTI, G. A. Prevalência De Imunodeficiência Viral Felina E Leucemia Viral Felina No Distrito Federal. Archives of Veterinary Scienc, v. 17, n. (supl.) Resumo 0902012.

MONTAÑO, P. Y.; GIZZI, A. B. R.; LEUTENEGGER, C.; BIONDO, A. W.; DITTRICH, R. L. Ocorrência De Coinfecções Em Gatos Domésticos Anêmicos e não Anêmicos. In: ANCLIVEPA, 34ํㅡㄴ CONGRESSO BRASILEIRO DA ANCLIVEPA - CBA, 2013, Nata-RN. 
MONTOYA, J. G. Laboratory diagnosis of Toxoplasma gondii infection and toxoplasmosis. The Journal of infectious diseases, v. 15, n. 185, p. 73-82, 2002.

MONTOYA, J. G.; LIESENFELD, O. Toxoplasmosis. Lancet, v. 363, n. 9425, p. 1965-1976, 2004.

NETTO, E. G.; ALEXANDRE, D. M.; GEORGE, R. A.; CARLOS, W. G. L.; ANA MARIA, R. F. Ocorrência de gatos soropositivos para Toxoplasma gondii Nicolle e Manceaux, 1909 (Apicomplexa: Toxoplasmatinae) na cidade de Niterói, Rio de Janeiro. Revista Brasileira de Parasitologia Veterinária, v. 12, n. 4, p. 145-149, 2003.

PENA, H. F.; SOARES, R. M.; AMAKU, M.; DUBEY, J. P.; GENNARI, S. M. Toxoplasma gondii infection in cats from Sao Paulo state, Brazil: seroprevalence, oocyst shedding, isolation in mice, and biologic and molecular characterization. Research in veterinary science, v. 81, n. 1, p. 58-67, 2006.

PINTO, L. D.; ARAÚJO, F. A. P.; STOBB, N. S.; MARQUES, S. M. T. I. Soroepidemiologia de Toxoplasma gondii em gatos domiciliados atendidos em clínicas particulares de Porto Alegre, RS, Brasil. Ciência Rural, v. 39 n. 8, p. 24642469, 2009.

RAJÃO, D. S.; BRAZ, G. F.; ALVES, F.; ALMEIDA, N. R.; MAZUR, C. Imunodeficiência viral felina. In: MARQUES JR, A. P. e HEINEMANN, M. B. (Ed.). Retroviroses dos animais domésticos. Belo Horizonte: FEPMVZ Editora, 1999. cap. 2, p.10-13.

RIVETTI JR, A. V. Retroviroses, Toxoplasma gondii e Mycoplasma haemofelis em gatos errantes e felinos selvagens do zoológico de Belo Horizonte - MG 2006. 38 (Dissertação). Escola de Veterinára, Universidade Federal de Minas Gerais, Belo Horizonte-MG.

RIVETTI JR, A. V.; CAXITO, F. A.; RESENDE, M.; LOBATO, Z. I. P. Avaliação sorológica para Toxoplasma gondii pela imunofluorescência indireta e detecção do vírus da imunodeficiência felina pela nested PCR em felinos selvagens. Arquivo Brasileiro de Medicina Veterinária e Zootecnia, v. 60, n. 5, p. 1281-1283, 2008.

ROSA, V. M.; OLIVEIRA, J. C. V.; BETTINI, C. M.; ALVARES, A. A. A. Estudo Epidemiológico De Infeccões Pelo Vírus Da Leucemia E Imunodeficiência Felina, Em Gatos Domésticos Do Município De Maringá. In: MARINGÁ, C.-C. U. D., VII EPCC Encontro Internacional de Produção Científica Cesumar, 2011, Maringá-PR.

SALANT, H.; MARKOVICS, A.; SPIRA, D. T.; HAMBURGER, J. The development of a molecular approach for coprodiagnosis of Toxoplasma gondii. Veterinary Parasitology, v. 146, n. 3-4, p. 214-220, 2007.

SALANT, H.; SPIRA, D. T.; HAMBURGER, J. A comparative analysis of coprologic diagnostic methods for detection of Toxoplama gondii in cats. American Society of Tropical Medicine and Hygiene, v. 82, n. 5, p. 865-870, 2010.

SILVA, A. V.; CASTRO, C. C.; FINGER, P. F.; SILVA, D. S.; TANIWAKI, S. A.; ULLMANN, L. S.; FISCHER, G.; VARGAS, C. S. G.; LIMA, M.; ARAÚJO JR, J. P.; HÜBNER, S. O. Ocorrência do subtipo $B$ do vírus da imunodeficiência felina em 
gatos domésticos da região sul do estado do Rio Grande do Sul, Brasil. Arquivo Brasileiro de Medicina Veterinária e Zootecnia, v. 66 n. 1, p. 1-6, 2014.

SILVA, C. C. Pesquisa de anticorpos anti-Toxoplasma gondii (Nicolle \& Manceaux, 1909) em felídeos selvagens nos municípios de capitão poço e Belém, Pará 2008. 91 (Dissertação). Programa de Pós-Graduação em Ciência Animal, Universidade Federal do Pará, Belém.

SILVA, F. R. C. Prevalência Das Infecções Pelo Vírus Da Leucemia Viral Felina E Da Imunodeficiência Viral Felina Na Cidade De Porto Alegre 2007. 57 (Dissertação). Pós-Graduação em Ciências Veterinárias da Faculdade de Veterinária, Universidade Federal do Rio Grande do Sul, Porto Alegre-RS.

SOBRINHO, L. S.; ROSSI, C. N.; VIDES, J. P.; BRAGA, E. T.; GOMES, A. A.; DE LIMA, V. M.; PERRI, S. H.; GENEROSO, D.; LANGONI, H.; LEUTENEGGER, C.; BIONDO, A. W.; LAURENTI, M. D.; MARCONDES, M. Coinfection of Leishmania chagasi with Toxoplasma gondii, Feline Immunodeficiency Virus (FIV) and Feline Leukemia Virus (FeLV) in cats from an endemic area of zoonotic visceral leishmaniasis. Veterinary Parasitology, v. 187, n. 1-2, p. 302-306, 2012.

SOBRINHO, L. S. V.; VIDES, J. P.; BRAGA, E. T.; GOMES, A. A. D.; ROSSI, C. N.; MARCONDES, M. Sorofrequência de infecção pelo vírus da imunodeficiência felina e vírus da leucemia felina em gatos do município de Araçatuba, São Paulo. Brazilian Journal of Veterinary Research and Animal Science, v. 48, n. 5, p. 3783832011.

STOJANOVIC, V.; FOLEY, P. Infectious disease prevalence in a feral cat population on Prince Edward Island, Canada. The Canadian Veterinary Journal, v. 52, n. 9, p. 979-982, 2011.

SUKHUMAVASI, W.; BELLOSA, M. L.; LUCIO-FORSTER, A.; LIOTTA, J. L.; LEE, A. C.; PORNMINGMAS, P.; CHUNGPIVAT, S.; MOHAMMED, H. O.; LORENTZEN, L.; DUBEY, J. P.; BOWMAN, D. D. Serological survey of Toxoplasma gondii, Dirofilaria immitis, Feline Immunodeficiency Virus (FIV) and Feline Leukemia Virus (FeLV) infections in pet cats in Bangkok and vicinities, Thailand. Veterinary Parasitology, v. 188, n. 1-2, p. 25-30, 2012.

TEIXEIRA, B. M.; RAJÃO, D. S.; HADDAD, J. P. A.; LEITE, R. C.; REIS, J. K. P. Ocorrência do vírus da imunodeficiência felina e do vírus da leucemia felina em gatos domésticos mantidos em abrigos no município de Belo Horizonte Arquivo Brasileiro de Medicina Veterinária e Zootecnia, v. 59, n. 4, p. 939-942, 2007.

TEIXEIRA, B. M. Identificação e caracterização do vírus da imunodeficiência felina de amostras obtidas de felinos mantidos em um abrigo na cidade de São Paulo 2010. 150 (Tese). Programa de Pós-graduação em Clínica Veterinária da Faculdade de Medicina Veterinária e Zootecnia da Universidade de São Paulo, São Paulo-SP.

TEIXEIRA, B. M.; HAGIWARA, M. K.; CRUZ, J. C.; HOSIE, M. J. Feline immunodeficiency virus in South America. Viruses, v. 4, n. 3, p. 383-396, 2012. 
TEMOCHE, L. F. C. Frequência de Toxoplasma gondii (Nicolle; Manceuax, 1909) em gatos (Felis catus, Linnaeus 1758) residentes em duas áreas distintas da américa latina 2012. 60 (Dissertação). Programa de Pós-graduação em Medicina Veterinária, Universidade Federal Fluminense, Niterói-RJ.

TENTER, A. M.; HECKEROTH, A. R.; WEISS, L. M. Toxoplasma gondii: from animals to humans. International journal for parasitology, v. 30, n. 12-13, p. 12171258, 2000.

TIAO, N.; DARRINGTON, C.; MOLLA, B.; SAVILLE, W. J.; TILAHUN, G.; KWOK, O. C.; GEBREYES, W. A.; LAPPIN, M. R.; JONES, J. L.; DUBEY, J. P. An investigation into the seroprevalence of Toxoplasma gondii, Bartonella spp., feline immunodeficiency virus (FIV), and feline leukaemia virus (FeLV) in cats in Addis Ababa, Ethiopia. Epidemiology and infection, v. 141, n. 5, p. 1029-1033, 2013.

VARGAS, C. S. G. Títulos de anticorpo da classe IgG anti - Toxoplasma gondii (Nicolle \& Manceaux, 1908) e de oocistos em fezes de gatos de rua (Felis catus - Linnaeus, 1758) em Curitiba, Paraná 2006. 73 (Dissertação). Pós-Graduação em Ciências Veterinárias Universidade Federal do Paraná, Curitiba-PR.

VIOL, M. A.; SOEIRO, C. S.; AQUINO, M. C. C.; FERREIRA, V. B. C.; YAMDA, D. I.; GARCIA, S. D.; BOMFIM, S. R. M. Ocorrência de Toxoplasma gondii em uma população de gatos domésticos (Felis catus) no município de Araçatuba-SP. Anais do 35\% Conbravet-Congresso Brasileiro de Medicina Veterinária [Internet]. 2008. [Acesso em 03 de julho de 2015].

ZANUTTO, M. S. Dinâmica da infecção toxoplásmica em felinos infectados pelo Vírus da Imunodeficiência Felina. 2005. 117 (Tese). Programa de Pós-graduação em Clínica Veterinária da Faculdade de Medicina Veterinária e Zootecnia, Universidade de São Paulo, São Paulo-SP.

ZULPO, D. L. Toxoplasma gondii e gatos domésticos: Uso de uma vacina para diminuir a eliminação de oocistiso e avaliação da reeliminação. 2014. 65 (Tese). Programa de Pós-graduação em Ciência Animal do Centro de Ciências Agrárias, Universidade Estadual de Londrina, Londrina-PR. 